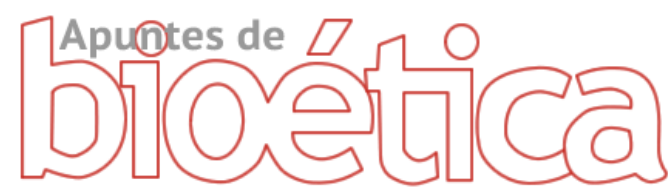

https://doi.org/10.35383/apuntes.v2i1.244

\title{
La capacidad jurídica de las personas con Síndrome de Down para poder donar órganos en el Perú
}

\author{
Aldo Alesandro Santome Sánchez ${ }^{1}$
}

\section{INFORMACIÓN DEL ARTÍCULO}

\section{Historia del artículo:}

Recibido el 22 de marzo de 2019

Aceptado el 15 de mayo de 2019

\section{Palabras claves:}

Capacidad Jurídica

Autonomía

Discapacidad

Donación de órganos

Modelo Social

Convención de Derechos de las Personas con Discapacidad

Síndrome de Down

\section{RESUMEN}

En el presente artículo se ha realizado un análisis jurídiconormativo sobre la capacidad de las personas con Síndrome de Down para manifestar su voluntad en caso de donación de órganos en el Perú, un trabajo que abre la posibilidad jurídica de aceptación del consentimiento conferido por el dador con Síndrome de Down. Para tal cometido, se ha efectuado un estudio conjunto de la legislación peruana y los tratados internacionales en Derechos Humanos ratificados por el Perú, que promueven un interés por el respeto a la autonomía de las personas con algún tipo de discapacidad.

The legal capacity of people with Down syndrome to be able to donate organs in Peru

\section{ABSTRACT}

\section{Keywords:}

Juridical capacity Autonomy Disability

Organ donation

Social Model Convention on the Rights of Persons with Disabilities Down's Syndrome
This article has carried out a legal-normative analysis on the ability of people with Down Syndrome to express their willingness in case of organ donation in Peru, a work that opens the legal possibility of acceptance of the consent conferred by the giver with Down syndrome. For such a comet, a joint study of Peruvian legislation and international human rights treaties ratified by Peru has been carried out, which promotes an interest in respecting the autonomy of people with some type of disability. 


\section{Introducción}

El mundo de las ciencias de la salud se ha vuelto un claro colaborador del Derecho en los últimos años; más allá de los progresos para hacer efectivo el derecho a la salud que todas las personas tenemos (así reconocido tanto en leyes internas como en tratados internacionales), también ha contribuido con nuevas complejidades que fuerzan al Derecho a ponerse a prueba $y$, de ser necesario, replantear la manera como se venía tratando una determinada situación.

Sin duda alguna, las personas con discapacidad suelen lidiar diariamente con diversas problemáticas, una realidad que -en los últimos años- ha despertado el interés del mundo jurídico en busca de una verdadera lucha por la reivindicación de los derechos humanos de esta población, quienes -en la mayoría de ocasiones- sufren de un trato discriminatorio por parte de los demás miembros de la sociedad y de entidades públicas.

No es para nada extraño conocer casos de personas con algún tipo de discapacidad, a las que se les ha negado, por ejemplo, el derecho de sufragio, viéndose impedidos de elegir a sus autoridades (Coordinadora Nacional de Derechos Humanos, 2016), o, del mismo modo, los derechos a solicitar un crédito bancario (Indecopi sanciona a Banco Falabella por discriminar a cliente con discapacidad, 2014), acceder a un trabajo digno (Universia Perú, 2015), o incluso a contraer nupcias (20 minutos, 2008); casos que resultan siendo cotidianos en la sociedad en que vivimos.

Frente a situaciones como las descritas, conviene plantear una serie de cambios dentro de la sociedad para una mejor defensa de los derechos fundamentales, los cuales, por definición, vendrían a ser una demarcación de lo "mío" frente a lo "tuyo", de lo individual frente a la comunidad estableciendo, de esta manera, los cimientos de una convivencia respetuosa y con un pleno respeto por la dignidad de las personas. Al respecto De Lora menciona, sobre la definición de derechos humanos, que son derechos subjetivos, que puede definirse como aquellas posiciones o estatus normativos que los individuos poseemos debido a nuestras relaciones con otros por obra de ciertas normas que nos colocan en una determinada posición (Martínez Martínez, 2006); sin embargo, somos de la idea que no podemos decir que "nacen" por obra y gracia de una norma; los derechos humanos son derechos que son válidos con independencia de si algún Congreso o Asamblea los reconoce, y es que son inherentes al ser humano, como menciona el Art. 1 de la Declaración Universal de los Derechos Humanos (1948) (Alexy \& García-Figueroa, 2007, pág. 21); sin embargo no por ello vamos a negar la relevancia del reconocimiento legal para hacer efectiva el pleno ejercicio de éstos, pues, solo de esa manera los derechos fundamentales llegan a concretarse en favor del individuo para garantizarle una calidad de vida acorde a su dignidad.

En base a la definición antes mencionada, podemos decir que la existencia de cuerpos normativos, constituidos precisamente como una suerte de garantía para delimitar la esfera de derechos de cada persona, es uno de los más grandes avances que se han realizado en defensa del individuo y su dignidad. Del mismo modo, dicha garantía de derechos significa correlativamente- un límite a las funciones del Estado, quien si bien debe asegurar aquellas prestaciones de servicios que satisfagan las necesidades básicas de los miembros de la sociedad, queda excluido de marcar injerencias en ciertas áreas específicas de la vida del individuo (Faundez, 1996). 
Sin embargo, habría que denotar las problemáticas que han surgido en relación a las personas con discapacidad, puesto que, como se puede apreciar del menoscabo de derechos ejemplificados con antelación, son varios los casos donde, tomando como base ideas prejuiciosas -por no decir arbitrarias- sobre la capacidad de las personas con discapacidad para tomar decisiones obre su imposibilidad de comprender o entender las situaciones que le rodean o que van a tener incidencia sobre ellas, son consideradas por el mismo sistema jurídico como sujetos con derechos limitables sin que haya una justificación realmente sólida ni sustentada, configurándose con ello, casos de discriminación hacia ésta población con cierta discapacidad (ya sea física, intelectual o psicosocial).

Hoy en día, el campo de las ciencias de la salud nos trae una nueva problemática. El caso se desarrolla en la provincia argentina de Mendoza, donde el señor Alfredo Gandur de 63 años, reconocido médico, alergista y experto en histocompatibilidad, es diagnosticado con poliquistosis renal, una enfermedad muy dura que lo hace someterse a un tratamiento de diálisis muy severo, mientras se encuentra a la espera de un trasplante que le pueda salvar la vida; el paciente tiene como única opción poder acceder a la donación de uno de los riñones de su hermano Jorge de 60 años; sin embargo solo existe una barrera que lo imposibilitaría, no es que su hermano se niegue a donarle un riñón, el consentimiento está por su parte, lo complicado del caso es que Jorge tiene Síndrome de Down, y un Juez Civil ha declarado que, como las normas lo declaran incapaz, no puede consentir la donación ${ }^{2}$.

Después de meses de controversia, el Ministerio de Justicia y Derechos Humanos de Argentina determinó que Jorge Gandur era

${ }^{2}$ http://www.clarin.com/sociedad/sindrome-down-permiten-necesitatrasplante_0 4yxjwK3gW.html "jurídicamente capaz" para decidir donarle uno de sus riñones a su hermano, tras comprobar que él, a pesar de su discapacidad intelectual, podía comprender el alcance de la ablación de uno de sus riñones, manifestando su consentimiento para la operación, expresando dicho deseo de manera clara ${ }^{3}$.

Más allá de cómo haya acabado la historia de los hermanos Gandur: ¿Era legítima una restricción para donar un órgano si la persona que quiere realizar dicho acto sufre de algún tipo de discapacidad intelectual? ¿Tendría que haberse solicitado la autorización de un tercero que certifique el deseo de Jorge de donar un riñón? ¿Se ha configurado un caso de discriminación? Ahora, si este caso hubiera ocurrido en el Perú, ¿Se hubiera resuelto de manera similar? ¿Qué dice la normativa interna sobre la donación de órganos cuando el donante es una persona con discapacidad? ¿Es compatible con los compromisos internacionales del Perú en materia de Derechos Humanos? En el presente artículo se darán respuesta a estas y otras interrogantes vinculadas, y con ello, más que hablar de los derechos de una minoría de la sociedad, se va a tratar de recordar el verdadero valor que nos da la condición de personas y de sujetos de derechos, nos referimos a la dignidad humana y la necesidad de su reivindicación en la sociedad actual.

\section{Resultados, análisis y discusión}

\section{UNA NUEVA MANERA DE VER A LA DISCAPACIDAD: EL MODELO SOCIAL}

Antes de plantear nuestro tema de fondo, resulta indispensable dejar en claro bajo qué conceptos nos vamos a desplazar para abordar dicha problemática.

\footnotetext{
${ }^{3} \mathrm{http} / / /$ www.docsalud.com/articulo/7388/concluyen-que-hombre-cons\%C3\%ADndrome-de-down-es-capaz-de-decidir-donar-su-
} ri\%C3\%B1\%C3\%B3n 
La visión que tiene la sociedad sobre las personas con discapacidad, ha pasado por todo un trayecto evolutivo que no ha hecho, sino afianzar o, mejor dicho, reivindicar la dignidad de las personas con discapacidad en relación a sus derechos dentro de la comunidad, pasando desde una perspectiva de prescindencia, hasta los nuevos conceptos que se manejan hoy en día desde una nueva perspectiva: la del modelo social.

\subsection{El modelo de la prescindencia}

Viene a ser el modelo más antiguo y originario, desde el cual, la discapacidad era considerada un castigo de origen divino, ya que imperaba la creencia de que las personas que sufrían de algún tipo de discapacidad estaban pagando algún mal ante los ojos de Dios, es decir, se le consideraba un ser humano indigno, que a la larga era una carga para sus propios padres y/o descendientes (Palacios, 2015).

De éste planteamiento se originó dos tratos impartidos a las personas que presentaba algún tipo de discapacidad: una era la marginación total de la comunidad, por considerar a las personas que tenían algún tipo de discapacidad como "indignos" o eran colocados en una posición de "hechizados" o "castigados por Dios"; lo cual llevaba a no solo a exiliar en el olvido a éstas personas frente al resto de la comunidad, sino muchas veces, éste trato alcanzaba a sus familiares, quienes eran vistos como los causantes de aquella "desdicha".

La otra acción impartida a estas personas era la eugenesia, esto es, buscaban la eliminación sistemática de las personas con discapacidad por ser consideradas como un retraso o inconveniente para el crecimiento y desarrollo de la sociedad al no colaborar según sus estándares con las necesidades de la comunidad, optaban por prescindir de esta población (Romañach, 2009, pág. 13). Dicha política claramente muestra la crueldad y arbitrariedad con la que eran tratadas las personas que sufrían alguna deficiencia funcional, puesto que se prefería matarlas que acoplarlas al resto de la población bajo la idea del costo que se utilizaría en su accesibilidad.

\subsection{El modelo rehabilitador}

Conforme fue desarrollándose las ciencias de la salud, la visión que se tenía de la discapacidad fue variando, por lo que el modelo de la prescindencia fue dejándose de lado. El nuevo modelo rehabilitador, o médicorehabilitador, acogía una realidad diferente, las personas con discapacidad dejaron de ser consideradas como sujetos innecesarios para la comunidad, planteándose la idea de que éstas pueden ser parte de la misma, siempre y cuando lleguen a ser "rehabilitadas" o "curadas" de su discapacidad, a la cual se comienza a ver como una enfermedad que debe ser curada una vez sea sometida a un determinado tratamiento médico (Romañach, 2009).

Como se puede apreciar, dicho planteamiento se contrapone claramente al modelo anterior, puesto que en lugar de marginar o deshacerse de una persona con discapacidad, ahora hay un compromiso de preocuparse por ella y su estado, aunque claro, como vamos a exponer a continuación, dicho modelo también tiene falencias. Agustina Palacios dice al respecto:

Si bien el modelo rehabilitador, en su momento, ha significado un avance importante en el ámbito del reconocimiento de ciertos derechos de las personas con discapacidad, es criticado por diversas razones. Fundamentalmente, en cuanto a su justificación teórica, se censura que el éxito de la integración 
que se persigue- si bien depende de una variedad de estrategias de asimilación- denota la existencia de una perturbada ideología a la que Sticker denomina 'idea social de la goma de borrar'. De este modo, el pasaporte de la integración pasa a ser la desaparición, o mejor dicho, el ocultamiento de la diferencia. Ello se debe a que la persona con discapacidad es considerada desviada de un supuesto estándar de normalidad, desconociendo que la configuración de lo estándar no es neutra, sino que se encuentra sesgada a favor de los parámetros físicos y psíquicos de quienes constituyen el estereotipo culturalmente dominante. (Palacios, 2015, pág. 13)

Como puede apreciarse, el problema con este modelo es que coloca a las personas con discapacidad bajo un rótulo de "anormalidad" que tiene que ser rehabilitada antes de poder acceder plenamente a la sociedad, ya sea mediante un tratamiento médico o mediante medidas legales para poder compensar esa supuesta incapacidad. Un ejemplo claro de esto último es la aplicación casi arbitraria de instituciones como la de la interdicción, donde se reemplaza la voluntad de la persona con discapacidad por considerar, en ciertos casos, de antemano, que no está capacitada para poder tomar decisiones, por lo que tiene que ser reemplazado por otra persona sin discapacidad (y por ende "normal") para que pueda decidir por ella, incluso sin tomar en cuenta la voluntad de la persona interdicta.

\subsection{El modelo social}

Como respuesta al modelo anterior, se ha venido desarrollando una nueva manera de ver el problema de la discapacidad. El pilar central de este modelo, es sindicar como principal causa de origen de la discapacidad, no a un factor médico, sino a un factor social. La sociedad, bajo esta perspectiva, es la que debe estar dispuesta a insertar a las personas con discapacidad, prestándoles servicios adecuados y asegurando que sus necesidades sean tenidas en cuenta dentro de la comunidad, esto es, se pasa de la "deficiencia" de la persona a la "deficiencia" de la sociedad, en otras palabras, es la sociedad la que debe ser "normalizada" (Palacios, 2015, pág. 14) y va a depender de los ajustes que se hagan en ella la plena inclusión de las personas con discapacidad.

Esto quiere decir que, a diferencia del modelo rehabilitador, para ser partícipe de la vida en comunidad ya no es necesario un "tratamiento" o una "cura" para la deficiencia física o intelectual de una persona, sino que ésta, bajo el modelo social, es plenamente parte de la misma, recayendo en la sociedad el deber de tornarse accesible a todos, incluyendo a las personas con discapacidad.

(Romañach, 2009, pág. 15) afirma que este modelo trata realmente de consagrar, ante todo, la autonomía de la persona con discapacidad para decidir respecto de su propia vida y, para ello, se centra en la eliminación de cualquier tipo de barrera, a fin de brindar una adecuada equiparación de oportunidades.

Por lo que este modelo apuesta es por salvaguardar de la dignidad de las personas con discapacidad, abogando por un respeto hacia su autonomía para decidir cómo y de qué manera participar en la sociedad. Para esto, naturalmente, la sociedad tiene que tomar ciertas medidas para ser accesible, ya que de lo contrario, se estaría alargando la discriminación que ha sufrido esta población a lo largo del tiempo. $Y$ hablamos de discriminación porque, como así lo apunta el artículo 2 de la Convención sobre los Derechos de las Personas con Discapacidad $^{4}$, la sociedad estaría excluyendo a

\footnotetext{
${ }^{4}$ Art.2.- Definiciones: (...) Por "discriminación por motivos de discapacidad" se entenderá cualquier distinción, exclusión o restricción por motivos de discapacidad que tenga el propósito o el efecto de obstaculizar o dejar sin efecto el reconocimiento, goce o ejercicio, en igualdad de condiciones, de
} 
las personas con discapacidad, al no hacerse accesible a ellos, ya que, como indicaba el modelo rehabilitador, ellos serían los que tendrían que "normalizarse" para ser parte de la vida en comunidad.

Finalmente, para ir cerrando la idea respecto del modelo social, Palacios menciona al respecto lo siguiente:

El modelo social de discapacidad presenta muchas coincidencias con los valores que sustentan a los derechos humanos, esto es: la dignidad, la libertad entendida como autonomía, en el sentido de desarrollo del sujeto moral, que exige entre otras cosas que la persona sea el centro de las decisiones que le afecten; la igualdad inherente de todo ser humanoinclusiva de la diferencia-, la cual exige, asimismo, la satisfacción de ciertas necesidades básicas y la solidaridad. (Palacios, 2015, pág. 15).

La búsqueda del modelo social es una búsqueda por una reivindicación plena de los derechos humanos, de la dignidad de la persona y un reconocimiento pleno a su autonomía; sin embargo, nos dice también que esta es una labor que nos involucra a todos como comunidad, buscando un derrocamiento de todas las barreras, muchas de ellas sociales, que diariamente impiden un pleno acceso a la plenitud de los derechos de las personas con discapacidad.

Entonces, hemos podido constatar, cómo a lo largo del tiempo ha venido ocurriendo una serie de cambios en materia de discapacidad y derechos humanos, partiendo de un modelo de marginación a un modelo que busca la inclusión plena; ahora, es momento de corroborar qué tipos de cambios normativos se han venido

todos los derechos humanos y libertades fundamentales en los ámbitos político, económico, social, cultural, civil o de otro tipo. Incluye todas las formas de discriminación, entre ellas, la denegación de ajustes razonables (..). produciendo como consecuencia de éste nuevo modelo.

\section{LA CONVENCIÓN SOBRE LOS DERECHOS DE LAS PERSONAS CON DISCAPACIDAD (CDPCD)}

Fruto del avance de los modelos sobre los que se miraba a la discapacidad, la Asamblea General de Naciones Unidas reconoció la necesidad un instrumento jurídico, de alcance internacional, que pudiera garantizar los derechos fundamentales de las personas con discapacidad y, del mismo modo, lograr que los Estados miembro se comprometieran a velar por construir sociedades más inclusivas y accesibles para ellos. Es, a raíz de la variación del modelo rehabilitador al modelo social de la discapacidad, que en diciembre de 2006 se firmó la Convención sobre los Derechos de las Personas con Discapacidad (en adelante, CDPCD), un instrumento internacional que, ante todo, busca realzar la dignidad y la autonomía de las personas con discapacidad dentro de una comunidad internacional, y garantizar un pleno ejercicio de sus derechos dentro de ésta.

Respecto del significado de la CDPCD dentro de la comunidad internacional, y de su misión con la lucha en beneficio de los derechos humanos de las personas con algún tipo de discapacidad, el Alto Comisionado para los Derechos Humanos de las Naciones Unidas menciona que la Convención "constituye un cambio paradigmático de actitud que va de la percepción de las personas con discapacidad como objetos de la caridad, del tratamiento médico y de la protección social, a la de sujetos de derechos capaces de reclamar esos derechos como miembros activos de la sociedad" ${ }^{\prime 5}$. Es

\footnotetext{
${ }^{5}$ Naciones Unidas. Informe de la Alta Comisionada de las Naciones Unidas para los Derechos Humanos sobre los progresos alcanzados en la aplicación de las recomendaciones contenidas en el estudio sobre los derechos humanos y la discapacidad. Documento Naciones Unidas A/HRC/4/75, 2007. Párrafo 21
} 
decir, se reconoce que dicha población ya no tiene que ser marginada ni ser tratada como "enferma", sino que debe ser incluida tomando en cuenta sus diferencias funcionales.

Del mismo modo se manifiestan Bregaglio y Salmón respecto de la relevancia de la CDPCD para la comunidad internacional:

"Esta Convención plantea un verdadero
cambio en el paradigma al recoger el
modelo social y, si bien son varios los
principios sobre los que se sustenta la
Convención, la autonomía resulta ser el
sustrato fundamental de todas sus
disposiciones normativas. Yes que, si no se
entiende que la finalidad última del ejercicio
de los derechos es conseguir la plena
autonomía de la persona, entonces, no se
podrá crear la necesaria institucionalidad
jurídica para que las personas con
discapacidad puedan disfrutar de sus
derechos en igualdad de condiciones que el
resto de la sociedad. Por tanto, todos los
espacios sociales deberán ser plenamente
inclusivos para que todos sus miembros
puedan participar (...)" (Bregaglio \&
Salmón, 2015).

Como ya dijimos, es el modelo social de la discapacidad el pilar principal de ésta Convención, lo que se demuestra, por ejemplo, dentro de su Preámbulo al mencionarse lo siguiente: "(...) la discapacidad es un concepto que evoluciona y que resulta de la interacción entre las personas con deficiencias y las barreras debidas a la actitud y al entorno que evitan su participación plena y efectiva en la sociedad, en igualdad de condiciones con las demás". Sobre éste punto, vale la pena mencionar que, según la Convención, el concepto de Discapacidad viene a formarse por dos factores: una deficiencia (que bien puede ser, como ya hemos mencionado, física, intelectual o psicosocial $)^{6}$ y la interacción de ésta con las diversas barreras y el entorno que se encuentran en la sociedad y que le impidan acceder con la plenitud de sus derechos en ella?.

Del mismo modo, líneas más adelante, en el mismo preámbulo, menciona que "la discriminación contra cualquier persona por razón de su discapacidad constituye una vulneración de la dignidad y el valor inherentes del ser humano"; además, se hace una clara mención a "la importancia que para las personas con discapacidad reviste su autonomía e independencia individual, incluida la libertad de tomar sus propias decisiones" con lo que refuerza la idea de la reivindicación de la

\footnotetext{
${ }^{6}$ Ahora bien, cabe la pena precisar lo siguiente, si bien no se pretende centrarse demasiado en el análisis de la palabra "discapacidad" vale la pena hacer una mención breve al término con la finalidad de remarcar una diferencia entre ésta definición, planteada por la CDPCD, y otros documentos emitidos por organismos de Naciones Unidas (más en específico, la Organización Mundial de la Salud, en adelante, la OMS) cuyas definiciones pueden demostrar la influencia del modelo rehabilitador al muchas veces entremezclar los conceptos de discapacidad y enfermedad. Al respecto, la OMS estableció en 1948 como definición de salud que esta era "un estado de completo bienestar físico, mental y social, no meramente la ausencia de malestar o enfermedad", lo cual llevaría a pensar que cualquier tipo de deficiencia vendría a ser considerado como enfermedad, lo cual negamos ya que aceptar dicha definición sería contravenir no solo otro instrumento internacional igualmente válido y vigente, sino que también sería contradecir lo que la misma OMS ha dictaminado en otro documento: la "Clasificación Internacional sobre Funcionalidad, Discapacidad y Salud" (CIF), donde se define a una deficiencia como "una pérdida o anormalidad( en términos estadísticos) de una parte del cuerpo o de una función fisiológica o mental", mientras que la discapacidad es definida como "un término paraguas que se utiliza para referirse a los déficits, las limitaciones en la actividad y las restricciones en la participación", entonces, es en la CIF donde se puede denotar una diferenciación de términos, identificando a la discapacidad como un término social más ya no como un término derivado del campo de la salud. Ver: (Palacios \& Romañach, El Modelo de la Diversidad: La bioética y los Derechos Humanos como herramientas para alcanzar la plena Dignidad en la Diversidad Funcional, 2006).

7 Al respecto de la definición de "barreras" que usamos en el desarrollo de éste trabajo, vale la pena aclarar la definición más detallada de éstas. De manera literal, la palabra "barrera" puede referirse a cualquier obstrucción para poder realizar determinada tarea o conseguir un determinado objetivo; dentro de éste trabajo vamos a extender aún más dicha definición; ahora, dichas barreras pueden ser físicas (como puede ser la ausencia de rampas en los establecimientos abiertos al público que le impiden a las personas con discapacidad física realizar un determinado trámite o acceder a un servicio), actitudinales (por ejemplo el prohibirle el acceso a una mujer con parálisis cerebral a una exposición de autos por temor de que otros asistentes se incomoden o se compadezcan de ella impiden que pueda ejercer plenamente sus derechos culturales), legales (el caso de impedirle el matrimonio entre personas con alguna discapacidad física, como puede ser una pareja de sordos), o sociales (entendidas como las condiciones materiales que afectan a las personas, como es el caso en que alguna de ellas no pueda acceder autónomamente a la propiedad porque se encuentra sometida a un régimen de interdicción). Ver: (Bregaglio, Constantino, \& Oca, , Manual para el Estudiante de la Clínica Jurídica en Discapacidad y Derechos Humanos de la PUCP, 2013, pág. 27)
} 
autonomía de dichas personas más allá de su deficiencia funcional.

Como queda visto, la Convención tiene como uno de sus principales objetivos la recuperación, dentro de la sociedad, de la autonomía de las personas con discapacidad, sobre las que ha venido imperando un trato discriminatorio en razón de su diversidad funcional respecto al resto de miembros de la sociedad; se busca dejar de lado ideas prejuiciosas sobre su capacidad de tomar decisiones o de discernir sobre ciertos temas. Ahora, la propia Convención menciona que "los Estados Partes se comprometen a asegurar $y$ promover el pleno ejercicio de todos los derechos humanos y las libertades fundamentales de las personas con discapacidad sin discriminación alguna por motivos de discapacidad", por lo que éste debe de ser un objetivo que el Estado peruano debe procurar su cumplimiento en legislación interna (la cual más adelante vamos a revisar).

\section{BREVES APUNTES SOBRE LAS PERSONAS CON SÍNDROME DE DOWN}

Mucho se habla sobre la capacidad de las personas con Síndrome de Down para comprender lo que ocurre en su entorno y, con ello, la posibilidad de discernir sobre cuestiones que le afectan de modo directo, sino recordemos en caso del señor Gandul que mencionamos en las primeras páginas de este artículo y que ha sido el caso que ha inspirado estas páginas.

Respecto a la causa generadora de esta deficiencia intelectual y sus principales características, la OMS ha manifestado lo siguiente:

"El síndrome de Down es una ocurrencia genética causada por la existencia de material genético extra en el cromosoma 21 que se traduce en discapacidad intelectual. Todavía no se sabe por qué ocurre esto. Esto puede deberse a un proceso de división defectuoso (Ilamado de no disyunción), en el cual los materiales genéticos no consiguen separarse durante una parte vital de la formación de los gametos, lo que genera un cromosoma más (llamado trisomía 21). Se desconoce la causa de la no disyunción, aunque guarda alguna relación con la edad de la embarazada. El material adicional presente influye en el desarrollo del feto $y$ resulta en el estado conocido como síndrome de Down. La incidencia estimada del síndrome de Down a nivel mundial se sitúa entre 1 de cada 1.000 y 1 de cada 1.100 recién nacidos. Las personas con síndrome de Down suelen presentar más problemas oculares que quienes no tienen esta alteración genética. Además, del 60\% al $80 \%$ tienen un déficit auditivo $y$ del $40 \%$ al $45 \%$ padecen alguna enfermedad cardíaca congénita. Otro motivo de preocupación se relaciona con factores nutricionales. Los niños con síndrome de Down presentan generalmente anomalías intestinales con mayor frecuencia que el resto y los que, además, padecen enfermedades cardíacas graves suelen mostrar un retraso en el desarrollo."

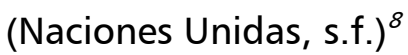

Como se puede ver, el Síndrome de Down, si bien puede traer complicaciones en la interacción de la persona con su entorno y con las personas que le rodean, no le impide llevar -

\footnotetext{
${ }^{8}$ Todo esto sin menospreciar las problemáticas en las funciones cognitivas (atención, senso-percepción, memoria, pensamiento- inteligencia, aprendizaje, lenguaje) como también funciones mentales; el síndrome de Down se tipifica como discapacidad intelectual con una representación importante entre la población con discapacidad con características particulares (como puede ser el que es estado que dura toda la vida, que comienza antes de los 18 años, que el funcionamiento intelectual general de la persona está considerablemente por debajo del promedio y que su conducta no alcanza el nivel de independencia personal y responsabilidad social que corresponde con su edad y cultura) que hace inevitable y necesaria la separación de las otras deficiencias mentales que están asociadas con la discapacidad mental propiamente dicha. Ver: (Comisión Nacional de Integración de las Personas con Discapacidad (CONADIS), 2016, pág. 1)
} 
hasta cierto punto- una vida independiente de otras personas, siendo que puede reconocerse capaz para la realización de múltiples funciones. Si bien, la manera en que una persona con esta anomalía congénita reacciona frente a los demás pudiera hacer creer que no tiene una clara percepción sobre su entorno, eso puede cuestionarse dependiendo del grado de afectación de dicho Síndrome 9 .

Del mismo modo, dentro del país tiene una gran relevancia un estudio sobre la capacidad de las personas con Síndrome de Down, tomando en cuenta que, según datos de CONADIS, hay actualmente más de 140000 personas inscritas en el Registro Nacional de Personas con Discapacidad que tienen dicha deficiencia, lo cual equivale a un $6,21 \%$ del total de inscritos, lo cual es una cifra considerable en comparación con las otras deficiencias intelectuales presentes entre las personas con discapacidad en el país (Comisión Nacional de Integración de las Personas con Discapacidad (CONADIS), 2016, pág. 6).

Es en razón de ello que vamos a analizar la legislación interna que rige actualmente la donación de órganos, y ver si es compatible tanto con la Constitución Política actual, como con tratados internacionales en materia de Derechos Humanos, para luego determinar cuál hubiera sido la decisión tomada por las autoridades judiciales en caso se presentara un caso similar al de los hermanos Gandur en el Perú.

\section{ASPECTOS EN LA LEGISLACIÓN INTERNA Y EXTERNA RESPECTO DE LAS PERSONAS CON DISCAPACIDAD $Y$ SUS DERECHOS DENTRO DE LA SOCIEDAD}

\footnotetext{
${ }^{9}$ Cabe destacar que solamente el $56 \%$ de las personas con Síndrome de Down están diagnosticadas con una afectación severa de éste, por lo que hay un $44 \%$ que tiene una afectación leve o moderada. Ver: (Comisión Nacional de Integración de las Personas con Discapacidad (CONADIS), 2016, pág. 6)
}

\subsection{Normas nacionales}

Primero es debido analizar las normas internas, y dar a conocer cómo las leyes peruanas amparan el derecho a la donación de órganos, y si esto impide o permite que personas con una discapacidad intelectual, como el Síndrome de Down, puedan o no donar órganos de prestar su consentimiento para ello.

\section{Constitución Política del Perú de 1993}

Solamente para hacer una comparación entre la Constitución vigente y sus ediciones anteriores, se debe decir que los términos en que está redactada la Constitución de 1993 reiteran en buena parte los derechos previstos por la Carta Magna de 1979, solo que, respondiendo a la ideología de tendencia neoliberal que predominaba en el gobierno de turno, se recortó de manera considerable todos aquellos derechos que significaban prestaciones del Estado a las personas (Rubio, 1999, pág. 19). Como menciona Samuel Abad, carecía de sentido modificar la parte dogmática de la Constitución de 1979, para ampliar o introducir nuevos derechos, bastaba con acudir a su Art 4 (cuyo contenido ahora está en el Art. 3 de la vigente) que permitiría la apertura a futuros derechos implícitos, derivados de la dignidad humana (Abad, 2006, págs. 25-26).

Sobre el tema que nos concierne en este trabajo, es propio mencionar lo estipulado en el Art.7 de la Carta Magna, donde se menciona que: "Todos tienen derecho a la protección de su salud, la del medio familiar y la de la comunidad así como el deber de contribuir a su promoción y defensa. La persona incapacitada para velar por sí misma a causa de una deficiencia física o mental tiene derecho al respeto de su dignidad y a un régimen legal de protección, atención, readaptación y seguridad". Sobre éste artículo se pueden decir muchas cosas, en primer lugar, que 
reconoce el derecho de las personas con discapacidad a la salud y a todas las prestaciones que conlleva; en segundo lugar, cuando se habla de discapacidad Ilama mucho la atención su tratamiento como "deficiencia", mas no se refiere a ella como una enfermedad, lo cual es un avance respecto a la percepción que se tiene de la discapacidad, acorde al modelo social; del mismo modo, es rescatable la mención que se hace al respeto de su dignidad, y por ende, de su autonomía; sin embargo, la mención a la "readaptación" hace pensar que la influencia del modelo rehabilitador no se ha dejado de lado del todo, puesto que estaría dando a entender que las personas con discapacidad tiene que "volver a adaptarse" a la sociedad como si se tratase de una enfermedad que debe ser curada antes integrarse nuevamente a la comunidad (bien sabemos que muchas deficiencias no pueden curarse, un ejemplo es el Síndrome de Down).

\section{Código Civil de 1984}

Sobre lo relacionado a la discapacidad dentro del Código Civil, nos vamos a centrar en lo referido a la calificación que se efectúa cuando se refiere a incapacidad, la cual puede ser "absoluta" o "relativa", ambas se encuentran reguladas en los Art. 43 y 44, respectivamente.

Respecto a la incapacidad absoluta, el Código Civil menciona lo siguiente:

\section{Art. 43.- Son absolutamente incapaces:}

1.- Los menores de dieciséis años, salvo para aquellos actos determinados por la ley

2.- Los que por cualquier causa se encuentren privados de discernimiento.

Cabe destacar que, antes de la promulgación de la Ley General de la Persona con Discapacidad, bajo el tercer inciso de éste artículo, los sordomudos, los ciegosordos y los ciegomudos que no podían expresar su voluntad de manera indubitable también eran considerados incapaces absolutos; sin embargo, la ley antes mencionada derogó dicho inciso en su única Disposición Complementaria Derogatoria por considerarse discriminatoria respecto de dichas personas.

El Art. 44 hace un listado más extenso respecto a la capacidad relativa, al mencionar lo siguiente:

Artículo 44.- Son relativamente incapaces:

1.- Los mayores de dieciséis y menores de dieciocho años de edad.

2.- Los retardados mentales.

3.- Los que adolecen de deterioro mental que les impide expresar su libre voluntad.

4.- Los pródigos.

5. - Los que incurren en mala gestión.

6. - Los ebrios habituales.

7.- Los toxicómanos.

8.- Los que sufren pena que lleva anexa la interdicción civil.

Podemos apreciar entonces que, respecto de las personas con algún tipo de discapacidad, estas podrían ser calificadas -muchas veces arbitrariamente- como incapaces, limitando así el pleno ejercicio de sus derechos fundamentales al considerarse que, al tener un "retardo mental", un "deterioro mental" 0 de encontrarse "privados de discernimiento", no están en condiciones de tomar decisiones sobre su vida y patrimonio $^{10}$.

\section{La Ley General de Salud (LGS)}

\footnotetext{
${ }^{10}$ Cabe destacar que el día lunes 6 de febrero de 2017, se presentó un Proyecto de Ley en el Congreso de la República del Perú para modificar una serie de artículos del Código Civil, donde se incluyen a los mencionados artículos 43 y 44, así como otros relacionados a la capacidad de ejercicio de las personas con discapacidad. En dicho proyecto de ley se busca garantizar la plena capacidad de ejercicio de todas las personas mayores de 18 años solamente existiendo restricciones a ésta por ley; del mismo modo, se garantiza que la discapacidad no comporta en ningún caso una restricción de la capacidad de ejercicio, y que las personas con discapacidad pueden designar representantes o contar con apoyos de su libre y voluntaria elección según las disposiciones del Código Civil y de las leyes especiales.
} 
La Ley No 26842, Ley General de Salud del Perú, hace al menos tres menciones explícitas a las personas con discapacidad. Por un lado el Art. V. de su Título Preliminar manifiesta que: "Es responsabilidad del Estado vigilar, cautelar y atender los problemas de desnutrición y de salud mental de la población, los de salud ambiental, así como los problemas de salud del discapacitado, del niño, del adolescente, de la madre y del anciano en situación de abandono social"; por otro lado, en su Art. 9 se menciona que: "Toda persona que adolece de discapacidad física, mental o sensorial tiene derecho al tratamiento y rehabilitación. El Estado da atención preferente a los niños y adolescentes. Las personas con discapacidad severa, afectadas además por una enfermedad, tienen preferencia en la atención de su salud". Lo cual podría dar a entender una influencia del modelo rehabilitador, puesto que se estaría sugiriendo la necesidad de rehabilitar o curar a las personas con discapacidad de su deficiencia, lo cual, muchas veces, como por ejemplo, el Síndrome de Down, es imposible, puesto que, como se dijo anteriormente, no tiene cura.

Por otro lado, lo rescatable de éste cuerpo legal referido a la donación de órganos, se hace mencionó en su Art.8:

"Toda persona tiene derecho a recibir órganos o tejidos de seres humanos vivos, de cadáveres o de animales para conservar su vida o recuperar su salud. Puede, así mismo, disponer a título gratuito de sus órganos y tejidos con fines de trasplante, injerto o transfusión, siempre que ello no ocasiones grave perjuicio a su salud o comprometa su vida. La disposición de órganos y tejidos de seres humanos vivos está sujeta a consentimiento expreso $y$ escrito del donante. Los representantes de los incapaces, comprendidos dentro de los alcances del Artículo 4 de esta ley ${ }^{11}$, carecen de capacidad legal para otorgarlo (...)".

Resulta curioso mencionar la última frase del menciona artículo, claramente está impide la posibilidad a las personas con discapacidad intelectual de realizar una donación de órganos, puesto que ni ellos (por ser incapaces según el Código Civil) ni sus representantes legales (por mandato de la LGS) podrían autorizar la donación, lo cual podría llevar, como fue en caso de los hermanos Gandul, a la muerte de un familiar que tenía la necesidad de un trasplante.

\section{Ley General de Donación y Trasplante de Órganos y/o Tejidos Humanos}

Años después de haberse emitido la LGS, se aprobó la Ley $N^{\circ}$ 28189, Ley General de Donación y Trasplante de Órganos y/o Tejidos Humanos. Dentro de esta norma se menciona, en su Art. 9, relacionado a los requisitos que han de cumplirse para que una persona pueda ser donante de órganos regenerables, que "los menores de edad o incapaces podrán ser donantes siempre que los padres o tutores, con el Juez competente, otorguen la autorización correspondiente"; por tanto, si lo que estaría sujeto a donación fuera sangre o médula ósea, se tendría que recurrir a la instancia judicial para llevarla a cabo; si el donante tiene Síndrome de Down, se le estaría dando una vía diferenciada por cuestión de su discapacidad, lo cual podría ser considerado un trato diferenciado que resulta ser ilícito, puesto que, en primer lugar, se

\footnotetext{
11"Artículo 4.- Ninguna persona puede ser sometida a tratamiento médico o quirúrgico, sin su consentimiento previo o el de la persona llamada legalmente a darlo, si correspondiere o estuviere impedida de hacerlo. Se exceptúa de este requisito las intervenciones de emergencia.

La negativa a recibir tratamiento médico o quirúrgico exime de responsabilidad al médico tratante y al establecimiento de salud, en su caso. En caso que los representantes legales de los absolutamente incapaces o de los relativamente incapaces, a que se refieren los numerales 1 al 3 del Artículo 44 del Código Civil, negaren su consentimiento para el tratamiento médico o quirúrgico de las personas a su cargo, el médico tratante o el establecimiento de salud, en su caso, debe comunicarlo a la autoridad judicial competente para dejar expeditas las acciones a que hubiere lugar en salvaguarda de la vida y la salud de los miles reglamento establece los casos y los requisitos de formalidad que deben observarse para que el consentimiento se considere válidamente emitido".
} 
necesita estar sujeto al control de los padres o de un tutor $y$, en segundo lugar, al someter dicho consentimiento a la validación por vía judicial, tardaría un tiempo considerable, que haría, en el caso de donar un órgano para un paciente que necesita una cirugía urgente -como en el caso de los hermanos Gandul, que se pierda una vida que pudo ser salvada oportunamente.

El siguiente artículo se torna más complejo, puesto que en el Art. 10 de la norma citada se menciona que, en caso de donar un órgano no regenerable, como es el caso de un riñón, es necesario tener como uno de los requisitos "ser mayor de edad, gozar de plenas facultades mentales y de un estado de salud adecuado, debidamente certificado por médicos especialistas distintos de los que vayan a efectuar la extracción y el trasplante, que les permita expresar su voluntad de manera indubitable. Los representantes de los menores o incapaces no tienen facultad para brindar consentimiento para la extracción de órganos y/o tejidos de sus representados". Respecto al artículo anteriormente mencionado, entran muchas dudas, comenzando por si la mención que se hace sobre la "plena facultad mental" y al "estado de salud adecuado" impediría que una persona con Síndrome de Down pudiera donar órganos bajo ésta ley.

Ya hemos visto, cómo desde el modelo social de la discapacidad se ha ido cuestionando este tipo de normas que tratan como "enfermedad" algo que en realidad es una deficiencia intelectual, por lo que resulta cuestionable que se considere, bajo la justificación de no estar en un "estado de salud adecuado", la posibilidad de donar a una persona, a sabiendas de que, con ello, se estaría obviando un consentimiento autónomo e informado $\mathrm{y}$, por tanto, completamente válido. Del mismo modo, en la parte siguiente del artículo, como en la LGS, también se estaría vetando las donaciones de personas que, bajo la figura de la incapacidad absoluta y relativa del Código Civil, estarían siendo consideradas como "incapaces", y asimismo, también estarían vetando la intervención de sus representantes.

\section{Ley General de la Persona con Discapacidad (LGPD)}

La ley No 29973, Ley General de la Persona con Discapacidad, es una ley publicada el 24 de diciembre del 2012, que buscaba ante todo, reivindicar los derechos y el status de sujeto de derecho de las personas con discapacidad, estableciendo, como menciona el Art.1 de dicha norma, un "marco legal para la promoción, protección y realización, en condiciones de igualdad, de los derechos de la persona con discapacidad, promoviendo su desarrollo e inclusión plena y efectiva en la vida política, económica, social, cultural y tecnológica". Esta norma, bajo una clara influencia del modelo social también, en su Art.2, deja de lado antiguas definiciones sobre la discapacidad, y reconoce como persona con discapacidad a aquella "con una o más deficiencias físicas, sensoriales, mentales o intelectuales de carácter permanente que, al interactuar con diversas barreras (...) no ejerza o pueda verse impedida en el ejercicio de sus derechos y su inclusión plena y efectiva en sociedad (...)", con lo que trata de demarcar sus diferencias con el modelo rehabilitador al mencionar que la causa de la discapacidad son las barreras que sumadas a las deficiencias funcionales de las personas producen una inaccesibilidad al pleno ejercicio de los derechos.

En dicho cuerpo normativo se hace mención a una serie de derechos sociales a los que las personas con discapacidad tienen acceso, entre ellos el derecho a acceder a centros de salud y recibir una atención adecuada a su situación; del mismo modo, se rescata la creación e intervención del Sistema para la 
integración de la Persona con Discapacidad (SINAPEDIS), órgano encargado de asegurar el cumplimiento de las políticas públicas orientadas a la intervención del Estado en materia de la discapacidad; del mismo modo se rescata la intervención de la CONADIS, como órgano con potestad sancionadora en el marco de lo dispuesto en la Ley 27444, Ley de Procedimiento Administrativo General.

\subsection{Normas internacionales}

Así como ya hemos revisado brevemente algunos cuerpos normativos internos y la manera en cómo perciben la capacidad de las personas con discapacidad, vamos a hacer un breve repaso a cómo éste fenómeno es contemplado desde el ámbito de los tratados internacionales a los cuáles el Perú se ha adherido; naturalmente, a los mencionados habría que agregar tanto la Declaración Universal de Derechos Humanos así como la Convención Americana de Derechos Humanos (más conocido como el Pacto de San José), que tienen como pilares la igualdad de derechos entre todas las personas y el respeto a la libertad individual de cada uno.

\section{Convención Interamericana para la Eliminación de todas las Formas de Discriminación contra las Personas con Discapacidad}

Este tratado, ratificado por el Estado peruano en 1999, menciona y deja en claro que su objetivo principal es la prevención y eliminación de todas las formas de discriminación contra las personas con discapacidad y propiciar su plena integración en la sociedad. Para dicho objetivo, los Estados parte se comprometen a adoptar todas las medidas necesarias para eliminar todo tipo de exclusión contra las personas con discapacidad y así, propiciar su plena integración en la sociedad.
Del mismo modo, algo que resulta interesante, puesto que en la siguiente sección vamos a volver sobre este punto, es la mención que hace el Art.1.2.b de la Convención, que resalta que:

"No constituye discriminación la distinción o preferencia adoptada por un Estado parte a fin de promover la integración social o el desarrollo personal de las personas con discapacidad, siempre que la distinción o preferencia no limite en sí misma el derecho a la igualdad de las personas con discapacidad y que los individuos con discapacidad no se vean obligados a aceptar tal distinción $o$ preferencia. En los casos en que la legislación interna prevea la figura de la declaratoria de interdicción, cuando sea necesaria y apropiada para su bienestar, ésta no constituirá discriminación".

Resulta curioso puesto que lo mencionado tenemos que relacionarlo con lo dispuesto el Art.7 de la Constitución, así como en los cuerpos normativos mencionados, ya que si bien hay que aplaudir todos los avances que se hacen a favor de la inclusión de las personas con discapacidad, esto no quiere decir que se vayan a aceptar también aquellas medidas que, bajo la justificación de protección a una población vulnerable, realmente lo único que hacen es restringir derechos arbitrariamente, sin tomar en cuenta la autonomía que éstos pueden ejercer en la toma de decisiones que les afecten.

\section{Convención de Derechos de las Personas con Discapacidad (CDPCD)}

Aunque ya hemos visto brevemente la razón de ser de ésta Convención, vamos a volver a hacer hincapié en este documento para marcar algunos puntos que consideramos relevantes para el desarrollo de éste artículo. 
Al respecto, resulta interesante la mención que se hace en el segundo y tercer inciso del Art. 12 de la CDPCD que mencionan que los Estados Parte reconocerán que las personas con discapacidad tienen capacidad jurídica en igualdad de condiciones en todos los aspectos de la vida y, del mismo modo, deberán adoptar las medidas pertinentes para proporcionar acceso a las personas con discapacidad al apoyo que pueda necesitar en el ejercicio de su capacidad jurídica.

Del mismo modo, respecto a la conducta de los profesionales médicos respecto de las personas con discapacidad se tiene en cuenta según el Art.25.f que tienen el deber prestar a las personas con discapacidad "atención de la misma calidad que a las demás personas sobre la base de un consentimiento libre e informado, entre otras formas mediante la sensibilización respecto de los derechos humanos, la dignidad, la autonomía y las necesidades de las personas con discapacidad a través de la capacitación y la promulgación de normas éticas para la atención de la salud en los ámbitos público y privado", lo cual da a entender que el personal de los establecimientos de salud no está exento de obligaciones de reconocimiento hacia la autonomía de las personas con discapacidad, debiendo velar por su ejercicio pleno.

En un sentido similar, aunque de manera más general, se pronuncia el Art.19.c al manifestar que:

"Los Estados Partes en la presente Convención reconocen el derecho en igualdad de condiciones de todas las personas con discapacidad a vivir en la comunidad, con opciones iguales a las de las demás, y adoptarán medidas efectivas y pertinentes para facilitar el pleno goce de este derecho por las personas con discapacidad y su plena inclusión $y$ participación en la comunidad, asegurando en especial que:

\section{(...) c) Las instalaciones y los servicios comunitarios para la población en general estén a disposición, en igualdad de condiciones, de las personas con discapacidad y tengan en cuenta sus necesidades".}

Naturalmente que dentro del rubro de "instalaciones y servicios comunitarios" encontramos a los establecimientos que brindan servicios de salud; además, éste artículo conlleva a que, para poder hablar de una plena inclusión y participación a la comunidad, primero se tendría que reconocer, antes que nada, la capacidad de las personas con discapacidad para vivir independientemente.

\subsection{La jerarquía constitucional de los tratados internacionales}

Como ya hemos visto brevemente, queda demostrado que el fenómeno de la discapacidad compromete al Perú a nivel internacional a realizar varias medidas para poder garantizar un pleno ejercicio de los derechos de las personas con discapacidad, cosa que no está muy presente en la legislación (sino recordemos los artículos 43 y 44 del Código Civil o la LGS); sin embargo, es preciso rescatar la relevancia de los tratados internacionales en materia de derechos humanos como instrumentos de jerarquía constitucional dentro de nuestro ordenamiento jurídico interno.

Al respecto, Marcial Rubio explica:

En otras palabras, se crean tres rangos de tratados, según la aprobación que reciben: unos tendrán rango constitucional, otros de ley y, los que aprueba el Presidente, lo tendrán de decretos supremos. Dos problemas aparecen 
aquí. El primero es que nosotros estamos convencidos de que la cuarta disposición final de la Constitución da rango constitucional a la Declaración Universal de Derechos Humanos y a los tratados y acuerdos internacionales sobre derechos humanos ratificados por el Perú pues la Constitución peruana no podría ser interpretada a la luz de normas inferiores a ella y dicha cuarta disposición final dice: 'Las normas relativas a los derechos y a las libertades que la Constitución reconoce se interpretan de conformidad con la Declaración Universal de Derechos Humanos y con los tratados y acuerdos internacionales sobre las mismas materias ratificadas por el Perú. (Rubio, El sistema Jurídico, Introducción al Derecho, 2009, pág. 139)

Al respecto, el Tribunal Constitucional había indicado hace unos años que, el hecho de que un tratado tenga rango constitucional no quiere decir, ni por asomo, que se pueda cuestionar la constitucionalidad de una norma interna desde el mismo tratado, dado que la misma Carta Magna debe de ser el último filtro de constitucionalidad; sin embargo, el rol de los tratados que versan sobre derechos humanos es otro, y es que, al tener rango constitucional, no solo forma parte del derecho interno (Art.55 de la Constitución), sino que con ello existe la obligación de interpretar los derechos y libertades reconocidas en la Constitución ${ }^{12}$.

Sin embargo, se ha considerado dentro de la más reciente jurisprudencia, tanto de la Corte Interamericana de Derechos Humanos ${ }^{13}$

\footnotetext{
${ }^{12}$ A este respecto, conviene recordar lo sostenido por este Tribunal en el sentido de que el establecimiento de la pirámide jurídica nacional se sujeta a dos criterios rectores: las categorías y los grados. Las primeras "aluden a un conjunto de normas de contenido y valor semejante o análogo" y los segundos "exponen una jerarquía existente entre las normas pertenecientes a una misma categoría". En la primera categoría de nuestro sistema jurídico se encuentran "las normas constitucionales y las normas con rango constitucional", distribuidas en grados, siendo la Constitución la norma de primer grado, las leyes de reforma constitucional las normas de segundo grado, y los tratados internacionales sobre derechos humanos, las normas de tercer grado - STC N 00032-2010-Al/TC.

${ }^{13}$ La Corte Interamericana de Derechos Humanos utiliza éste término por primera vez en el caso Myrna Mack Chang Vs Guatemala del 25 de noviembre de 2003 .
}

como del mismo Tribunal Constitucional del Perú14, el llamado "Control de la Convencionalidad", mediante el cual los jueces del Poder Judicial están en la obligación de preferir las nomas de las Convenciones Internacionales de Derechos Humanos a las normas propias de su ordenamiento interno como respuesta a las obligaciones internacionales por parte del Estado peruano.

Para ser más específico, el Tribunal Constitucional menciona que:

"Demostrada la vulneración de las disposiciones supranacionales resulta necesario adecuar el derecho interno a los tratados. Esto implica que si la normativa doméstica (legislativa, administrativa o de cualquier otro carácter) y las prácticas estaduales de cualquiera de los tres poderes, no garantizan los derechos fundamentales reconocidos en el derecho internacional, el Estado debe adecuarlas o, en su caso, suprimirlas y crear garantías que verdaderamente protejan los derechos fundamentales. No estamos más que ante el deber general del Estado de adecuar su derecho interno (artículo 2 de la Convención Americana sobre Derechos Humanos) $)^{15}$.

Es por ello que se puede concluir que la legislación interna respecto de la posibilidad de poder permitirle a las personas con Síndrome de Down donar órganos en caso de consentir dicha intervención, debería de ajustarse interpretativamente tanto a lo señalado en Convención Interamericana para la Eliminación de todas las Formas de Discriminación contra las Personas con Discapacidad como en la CDPCD, velando porque se les considere como personas plenamente capaces de tomar decisiones sobre sí mismos o, en casos excepcionales (donde por la

${ }^{14}$ STC. Nº 04617-2012-PATTC 
severidad de la deficiencia sea imposible denotar la voluntad del donante), requiriendo los apoyos necesarios para llevar esto a cabo, siempre que no signifique el perjuicio de un respeto pleno a su voluntad.

5. UNA VISIÓN A FUTURO: SOBRE EL PATERNALISMO $Y$ EL RESPETO A LA AUTONOMÍA DE LAS PERSONAS CON DISCAPACIDAD

Hemos visto cómo, en razón de lo mencionado y ratificado por el Estado peruano en tratados internacionales, hay una tendencia hacia el reconocimiento de la voluntad de las personas con discapacidad a nivel mundial; sin embargo, conviene ahora hacer una breve reflexión sobre lo que éste reconocimiento a la autonomía significa.

Hemos visto cómo en la legislación interna aún existen muchos retazos de discriminación hacia las personas con discapacidad, en el sentido de que, como ya se dijo, se les considera de antemano como personas no capaces para la toma de decisiones ( si no basta recordar la clasificación que sobre la capacidad de ejercicio hace el Código Civil).

Sobre lo anterior, se podría entender dichas medidas si las relacionamos con el modelo rehabilitador de la discapacidad, y es que, como el Estado interpreta que las personas con discapacidad están en una situación de "necesidad" y que no están habilitadas para tomar decisiones lo más apropiado es evitar que asuman riesgos para sí mismos.

El problema de dicho planteamiento es que se está obviando todo rastro de autonomía de dichas personas, es decir, se está cayendo arbitrariamente en políticas paternalistas, es decir, medidas que, en principio, plantean "la interferencia en la libertad de acción de una persona justificada por razones que se refieren exclusivamente al bienestar, al bien, a la felicidad, a las necesidades, a los intereses o a los valores de la persona coaccionada" (Dworkin, 1990).

Con lo dicho anteriormente no se está diciendo que cualquier política paternalista sea desdeñable, al contrario, es necesaria ciertas medidas de carácter paternalista para el correcto funcionamiento de la comunidad, así como para la seguridad de sus miembros, por ejemplo, el clásico ejemplo del uso obligatorio del casco en caso uno se está desplazando en motocicleta si bien se está restringiendo la libertad de no querer usar el casco, se prioriza la posible afectación a la salud y la vida imponiendo una regla de modo previsional. Del mismo modo, el uso del semáforo también es una medida paternalista, puesto que limita el tránsito de los vehículos temporalmente, sin embargo, nadie cuestionaría la idea de colocar semáforos en las calles, pues se reconoce de dicha limitación de la libertad de tránsito es necesaria para un correcto y seguro transporte.

El problema radicaría cuando se imponen ciertas medidas paternalistas que se encuentren desproporcionadas respecto de a quiénes se aplica en un caso determinado., no encontrándose justificación a su aplicación (Gascon, 2007, págs. 1-17). Se entendería, desde nuestra perspectiva, que dichas medidas solamente se encuentran habilitadas cuando se comprueba, de manera fehaciente, que la voluntad de la persona sobre la que se quiere imponer dicha medida no se encuentra libremente ejercida del todo, o cuando la persona no es capaz de evaluar consistentemente el grave riesgo que su conducta conlleva consigo misma (Beauchamp \& Almeder, 1979). 
Volviendo al tema central de éste artículo, la cuestión es dilucidar caso por caso si es que la persona con discapacidad está manifestando libremente su voluntad, cuando fuera plenamente informado de los beneficios como de los contratiempos que podría tener.

Ahora, si las personas con discapacidad tienen que tener el reconocimiento como personas autónomas capaces de decidir sobre sí mismos, entonces, podemos concluir que la razón de ser de las normas paternalistas que sobre ellos se venía ejerciendo, y que en muchos casos no hacían sino aumentar ciertos prejuicios sobre la real capacidad de discernimiento de éstas, no tenían el sustento necesario, por lo que ameritaría su revisión a nivel legislativo.

Es entonces que, como bien apunta Benda en relación al último fin del Estado, "el Estado respetará al ser humano cuya dignidad se muestra en el hecho de tratar de realizarse en la medida de sus posibilidades" (Benda, 1996, pág. 125). Es así las personas que tienen una discapacidad intelectual, como el Síndrome de Down, deben tener la oportunidad de desarrollarse hasta donde sus limitaciones se lo permitan y lograr una vida en común satisfactoria o al menos soportable (Benda, 1996).

Esa parece ser la tendencia respecto de los próximos años, velando siempre por un respeto, más que a la autonomía, a la dignidad de la persona. Una dignidad que se entiende debe de ser el fin último de Estado, no solo tomando como base la misma Constitución, sino también instrumentos internacionales que no hacen sino velar por un compromiso verdadero en busca del reconocimiento pleno a los derechos de las personas, sobre todo respecto a poblaciones que por años han sido marginadas del ámbito comunitario, como las personas con discapacidad.
Entonces, si una persona con Síndrome de Down acude ante la llamada de un familiar con la intención de donarle un órgano ante una emergencia, el Estado peruano, según lo que hemos visto, tendría que considerarlo como una persona plenamente capaz para expresar su deseo de realizar la donación. Ahora, tomando en cuenta la afectación que el Síndrome de Down haya causado en la persona en el caso concreto, se tendría que evaluar si es necesario también que se imponga un sistema de apoyos para la persona; sin embargo, cabe resaltar que éstos no deberán buscar "reemplazar" su voluntad, sino tan solo "colaborar" con una mayor dilucidación de ésta. Si bien la legislación nacional prohíbe que los incapaces puedan donar órganos no regenerables, habría que contemplar sistemáticamente dicha norma con los tratados internacionales ratificados por el Perú para que, de este modo, no se pongan trabas en cuanto a su acceso a los establecimientos de salud, su trato con el personal, y con su consentimiento respecto de la donación.

Si llegamos a la idea de que las personas con discapacidad son tan capaces como una persona que no tenga ninguna deficiencia, entonces más allá de una simple igualdad formal, se podría llegar a una igualdad real, cotidiana, que busque cada día mejorar la manera de cómo se entienden y viven los derechos fundamentales en sociedad.

\section{Conclusiones}

La visión de la discapacidad ha ido evolucionando con el paso de los años, pasando de un modelo que buscaba prescindir y marginar a las personas con discapacidad, hacia el modelo social que busca ante todo reivindicar el papel de dichas personas en la comunidad, velando porque sea la misma comunidad la que 
desarrolle vías de accesibilidad para el pleno ejercicio de sus derechos.

La legislación actual en materia de donación de órganos, ve imposible el hecho de que una persona con discapacidad intelectual pueda realizar un consentimiento informado para fines de efectivizar una donación, esto debido a la incapacidad legal asignada a estas personas por el Código Civil.

El Estado Peruano se ha comprometido internacionalmente a una serie de Convenios Internacionales en materia de Derechos Humanos. Los jueces, en razón del control de convencionalidad tienen el deber de dar prioridad a dichos compromisos internacionales sobre la legislación interna. En ese sentido, se le tendría que dar prioridad a lo estipulado en el Convenio de Derechos de las Personas con Discapacidad que, basado en el modelo social, estipula la relevancia que tiene la voluntad de las personas con discapacidad en la toma de decisiones.

La actual legislación vigente en el Perú, está basada en el modelo rehabilitador de la discapacidad, que sostiene la necesidad de medidas paternalistas para las personas consideradas como "enfermas" y "necesitadas de ayuda"; sin embargo, como hemos visto, dichas medidas no se encuentran justificadas, por la considerable afectación de la voluntad de las personas con discapacidad.

Es debido un cambio en la legislación que asimile mejor el contenido de los Convenios Internacionales ratificados por el Estado en materia de Discapacidad, a fin de asegurar un respeto pleno a la autonomía y la dignidad de dichas personas.

\section{Bibliografía}

20 minutos. (02 de Octubre de 2008). Perú negó el matrimonio a dos sordomudos por no poder decir 'sí quiero. Obtenido de http://www.20minutos.es/noticia/416909/ 0/matrimonio/sordomudos/peru/

Abad, S. (2006). Constitución y Procesos Constitucionales. Lima.

Alexy, R., \& García-Figueroa, A. (2007). StarTrek y los Derechos Humanos. Valencia.

Beauchamp, T., \& Almeder, R. (1979). On Coercive Justifications for Coercive Genetic Control. En J. Humber , Biomedical Ethics and the Law (pág. 388). New York: Plenum Press.

Benda, E. (1996). Manual de Derecho Constitucional. Madrid: Marcial Pons.

Bregaglio, R., \& Salmón, E. (2015). Nueve Conceptos Claves para Entender la Convención sobre los Derechos de las Personas con Discapacidad. Instituto de Democracia y Derechos Humanos de la Pontificia Universidad Católica del Perú, 6.

Bregaglio, R., Constantino, R., \& Oca, D. (2013), Manual para el Estudiante de la Clínica Jurídica en Discapacidad y Derechos Humanos de la PUCP. Lima: Instituto de Democracia y Derechos Humanos de la Pontificia Universidad Católica del Perú.

Comisión Nacional de Integración de las Personas con Discapacidad (CONADIS). (2016). Informe Temático N², "El Síndrome de Down en el Perú.

Coordinadora Nacional de Derechos Humanos. (Abril de 21 de 2016). Mesa de Discapacidad y Derechos CNDDHH. 
Obtenido de Exigen a la ONPE garantizar condiciones que aseguren el derecho al voto de las personas con discapacidad: http://derechoshumanos.pe/2016/04/exig en-a-la-onpe-garantizar-condiciones-queaseguren-el-derecho-al-voto-de-laspersonas-con-discapacidad/

Dworkin, G. (1990). Paternalismo. En J. Betegón, \& J. de Páramo, Derecho y Moral (pág. 148). Barcelona: Ariel.

Faundez, H. (1996). El sistema interamericano de protección de derechos humanos. Jurídica Venezolana.

Gascon, M. (2007). "¿Pueden el Estado adoptar medidas paternalistas en el ámbito de la protección de la salud? Albacete: En Humanitas: Humanidades Médicas, Tema del mes on-line.

Indecopi sanciona a Banco Falabella por discriminar a cliente con discapacidad. (29 de Enero de 2014). Gestión. Obtenido de http://gestion.pe/empresas/indecopisanciona-banco-falabella-discriminarcliente-discapacidad-2087631

Martínez Martínez, F. (2006). Lora del Toro, Pablo de, Memoria y frontera. El desafío de los derechos humanos. Boletín mexicano de derecho comparado, 24.

Naciones Unidas. (s.f.). Día Mundial del Sindrome de Down: 21 de Marzo. Obtenido de http://www.un.org/es/events/downsyndro meday/background.shtml

Palacios , A., \& Romañach, J. (2006). El Modelo de la Diversidad: La bioética y los Derechos Humanos como herramientas para alcanzar la plena Dignidad en la
Diversidad Funcional. Coruña: Ediciones Diversitas.

Palacios, A. (2015). Una Introducción al Modelo Social de Discapacidad y su Reflejo en la Convención Internacional sobre los Derechos de las Personas con Discapacidad. Nueve Conceptos claves para entender la Convención de Derechos de las Personas con Discapacidad, 9-33.

Romañach, J. (2009). Bioética al Otro Lado del Espejo: La Visión de las Personas con Discapacidad Funcional y el Respeto a los Derechos Humanos. Coruña: Ediciones Diversitas-AIES.

Rubio, M. (1999). Para Conocer la Constitución de 1993. Lima: Fondo Editorial de la Pontificia Universidad Católica del Perú

Rubio, M. (2009). El sistema Jurídico, Introducción al Derecho. Lima: Fondo Editorial de la Pontificia Universidad Católica del Perú.

Universia Perú. (30 de Setiembre de 2015). Sólo el $15 \%$ de personas con discapacidad en el Perú tiene trabajo. Obtenido de http://noticias.universia.edu.pe/portada/n oticia/2015/09/30/1131766/solo-15personas-discapacidad-peru-trabajo.html. 